\title{
EL DERECHO DE LA BIOÉTICA EN FRANCIA ${ }^{1}$
}

\section{Luz Monge Talavera}

Doctora en derecho por la Universidad de París.

\section{INTRODUCCIÓN ${ }^{2}$}

L

os fulgurantes progresos de las ciencias biomédicas realizados a partir de los años setenta, aproximadamente, han

originado lo que actualmente se conoce como la revolución biomédica: de los trasplantes de órganos al nacimiento del bebé probeta, de la fecundación in vitro a la congelación de embriones humanos; de los tests de diagnóstico genético prenatal o posnatal a la terapia genética, del nacimiento de Dolly, la primera oveja clonada, a la clonación de seres humanos con fines reproductivos o incluso con fines terapéuticos.

Acontecimiento igualmente remarcable es la determinación de la secuencia del genoma humano, lo que permitirá comprender la estructura de los genes y su rol en el control de los mecanismos de reproducción, desarrollo, enfermedades y de la muerte. Parecería, entonces, que la creación del hombre perfecto y el mejoramiento de la especie no son más mitos. Asimismo, la utilización

1 Estudio realizado como parte del cuadro de proyectos del Instituto de Investigación de la Universidad de Lima.

2 Todas las traducciones han sido hechas por la autora del presente trabajo. 
de tests de diagnóstico de predicción podría modificar la situación de las personas en sus relaciones laborales y alterar los sistemas de protección, como los seguros.

$\mathrm{El}$ avance en el conocimiento científico ha traído como consecuencia una profunda modificación de la relación entre el médico y su paciente. Comprobamos que el objeto de la medicina no se circunscribe más a curar o tratar las enfermedades. La ciencia ha transferido al hombre nuevos poderes sobre la creación y la destrucción de la vida humana, con lo que se da lugar a la reivindicación de un nuevo orden de "derechos": del derecho a no procrear al derecho a procrear, del derecho a concebir un hijo al derecho a decidir ciertos caracteres del hijo que se desea concebir, del derecho a nacer al derecho a morir, pasando por el derecho a no nacer enfermo o inválido.

Ante el conflicto de valores revelado por el progreso de las ciencias biomédicas, ciertos países han adoptado una posición y han promulgado leyes de bioética nacionales. Tal es el caso de la legislación francesa.

\section{FORMACIÓN DEL DERECHO FRANCÉS DE LA BIOÉTICA}

Francia ha elaborado un cuadro jurídico que, en el plano del derecho comparado, constituye uno de los más completos del mundo ${ }^{3}$. El legislador francés ha determinado las fronteras entre aquello que puede ser permitido y aquello que debe ser prohibido. Se han elevado murallas a fin de

3 Esta reglamentación está compuesta por un conjunto , de normas adoptadas entre 1988 y 1994 e insertadas en el Código Civil, en el Código de la Salud Pública y en la Ley de Informática y Libertades. evitar siniestras amenazas y, paralelamente, se ha dado luz verde a las perspectivas positivas abiertas por la ciencia y la técnica. El objetivo es asegurar el libre y completo desarrollo de la persona.

Los cuestionamientos acerca de los progresos realizados en el dominio de las ciencias de la vida se remontan a más de 20 años. Sin embargo, la construcción del denominado derecho de la bioética no ha sido, como lo veremos, empresa de fácil realización.

Es a partir de 1980 que se instaura un verdadero debate en la sociedad francesa. Los poderes públicos, el legislador y las comunidades científica y universitaria se sumergen entonces en la reflexión sobre la naturaleza de las reglas de ética biomédica o jurídicas, debiendo regir la aplicación de los progresos de las ciencias biomédicas sobre el ser humano. Para algunos autores es suficiente la ética y la deontología médica; para otros, ellas adolecen de fuerza constrictora ${ }^{4}$.

La creación, en 1983, por decreto del presidente de la República, del Comité Consultivo Nacional de Ética para las Ciencias de la Vida y de la Salud ${ }^{5}$ institucionali-

4 Actes du colloque Génétique, procréation et droit. Actès sud, 1985; Comité Consultatif National D'ethique. Avis sur les problèmes étbiques nês des techniques de reproduction artificielle 3, 23 de octubre de 1984; Id. Avis relatif aux recherches et utilisation des embryons bumains in vitro à des fins médicales et scientifiques 8, 15 de diciembre de 1989; BAUDOUIN, Jean-Louis y Catherine LABRUSSE-RIOU. Produire l'bomme: de quel droit? Étude furidique et éthique des procréations artificielles. Paris: PUF, 1987; TERRÉ, François. L'enfant de l'esclave. Génétique et droit. París, Flammarion, 1987; BYK, Christian. Procréation antificielle où en sont l'étbique et le droit? Paris, Masson, 1989.

5 Francia ha sido el primer país del mundo en crear, por decreto del presidente de la República, un Comité Nacional de Ética, mediante el decreto 83-132 del 20 de febrero de 1983. Su existencia ha sido consagrada por las leyes bioéticas de 1994 . 
za las reflexiones "bioéticas"6. La constitución de este organismo es una etapa fundamental en la toma de conciencia de la necesidad de una reflexión colectiva sobre las incidencias de los progresos científicos en su aplicación a la medicina.

Desde 1984 , los poderes públicos inician la tarea de identificar los riesgos concernientes al desarrollo de la biomedicina y sus posibles soluciones. Pero la oportunidad de la elaboración de una ley suscita múltiples reticencias ${ }^{7}$. Es recién en 1986 que el gobierno francés se compromete definitivamente en la vía de la construcción legislativa $^{8}$. Entre 1988 y 1993 se presentan diversos informes ante el gobierno y el Parlamento nacional ${ }^{9}$. Ellos dieron lugar a la elaboración de tres proyectos de ley relativos a la ética biomédica. La adopción del texto final exigió la intervención de una comisión mixta paritaria. El 27 de julio de 1994, el Consejo Constitucional de ese país pronunció finalmente la declaración de su conformidad a la Constitución ${ }^{10}$.

6 El comité está encargado de dar opiniones sobre los problemas éticos originados por el progreso del conocimiento científico en el dominio de la biología, la medicina y la salud, y publicar recomendaciones sobre esos temas.

7 El profesor Jean Carbonnier hace un llamado a la prudencia en estos términos: "La ley produce efectos simbólicos que traspasan largamente sus efectos directos, no conviene legislar". Actes du colloque génétique, procréation et droit. Actes Sud, 1985, p. 79.

8 En 1986 el primer ministro Jacques Chirac solicita al Consejo de Estado "profundizar las reflexiones en el plano jurídico".

9 En 1991 la publicación del informe intitulado Sciences de la vie: de l'éthique au droit presentado por Guy Braibant, del Consejo de Estado. En 1991 la presentación del informe Aux frontieres de la vie: une étbique biomedicale a la française, establecido por Noelle Lenoir. En 1992 Les sciences de la vie et les droits de l'bomme, preparado por el senador Franck Sérusclat. En 1993 La vie en questions: pour une éthique biomedicale, del senador Jean-François Mattei.

10 Journal Officiel, 29 de junio de 1994, p. 11024.
El paso de la ética al derecho se opera al fin el 29 de julio de 1994, con la promulgación de las leyes llamadas de bioética: ley 94-653 relativa al respeto del cuerpo humano y ley $94-654$ relativa al don y a la utilización de los elementos y productos del cuerpo humano, a la asistencia médica a la procreación y al diagnóstico prenatal.

Las disposiciones consagradas forman el zócalo de la legislación francesa en el dominio de la ética biomédica. Ellas definen un régimen jurídico de la utilización de técnicas médicas. Algunos de sus principios son objeto de un consenso internacional, otros reflejan más bien el espíritu de la tradición cultural y jurídica del pueblo francés.

Según la doctrina, las nuevas disposiciones constituyen una suerte de pacto social sobre la utilización del cuerpo humano con fines médicos ${ }^{11}$. Ellas afirman solemnemente grandes principios, entre los cuales cabe resaltar el de la "primacía de la persona" y aquel que consagra el "respeto de su dignidad". En efecto, el artículo 16 del Código Civil, redactado en forma de declaración de principios, establece que "la ley asegura la primacía de la persona, prohíbe todo atentado a su dignidad y garantiza el respeto del ser humano desde el comienzo de su vida".

Estos principios garantizan la protección de la persona considerada en una $\mathrm{di}$ mensión individual: ante el peligro de su instrumentalización ${ }^{12}$, la ley consagra un estatuto civil del cuerpo humano. Dichos

11 CORNU, Gérard. Droit civil, introduction, les personnes, les biens. 8a. edición. Ed. Montchrestien, 1997, No 480 , p. 169.

12 En nuestro tiempo el hombre no es sólo el sujeto titular de derechos y obligaciones. Actualmente es percibido como un ser biológico susceptible de explotación no solamente para la aplicación de las técnicas de procreación asistida sino también para las experimentaciones y para las necesidades terapéuticas. 
principios fundan igualmente la protección de la persona concebida en una dimensión colectiva: ante los riesgos de la eugenesia, resultado de los progresos de la genética, la ley asegura la protección de la especie humana (item 3). Los mismos postulados encuadran la intervención médica en materia de procreación (ítem 4). El interés subyacente es la protección del ser humano y de la persona humana como fines en sí mismos.

\section{PROTECCIÓN DE LA PERSONA HUMANA}

Las disposiciones jurídicas conciernen al cuerpo humano desde que este funda la persona humana. Pero dado que la persona no se circunscribe a su carácter corporal tangible, el legislador la enfoca también desde el punto de vista de su identidad genética y en el supuesto de que esta última pueda ser modificada, toma en cuenta las posibles consecuencias sobre las otras generaciones.

La protección de la persona humana aparece entonces como el postulado sine qua non de la protección de la especie humana, desde que las manipulaciones eventuales sobre aquella podrían tener repercusiones sobre otras personas. Es dentro de esta perspectiva que las leyes bioéticas vinculan el cuerpo humano a la persona (item 3.1 ) y la persona a su patrimonio genético (îtem 3.2).

\subsection{El respeto del cuerpo bumano}

Las leyes del 29 de julio de 1994 definen un estatuto civil del cuerpo humano, que ha sido insertado en el capítulo II del título 1 del libro I del Código Civil intitula- do: "Del respeto del cuerpo humano"13. Se trata de principios generales, de orden público y de carácter imperativo destinados a proteger a la persona preservando su cuerpo.

Las normas que forman parte de ese capítulo rinden cuenta del vínculo estrecho e indisoluble entre la persona y su cuerpo. Así aparece que si debemos respeto al cuerpo humano es porque el cuerpo es la propia persona. A fin de salvaguardar su dignidad, el artículo 16-1 del Código Civil proclama que "cada uno tiene derecho al respeto de su cuerpo". Ese derecho encuentra su fuente primera y fundamental en el artículo 16, que asegura la primacía de la persona, prohíbe todo atentado a su dignidad y garantiza el respeto del ser humano desde el comienzo de su vida.

Conviene notar que el artículo 16-1 se limita a enunciar que "cada uno tiene derecho al respeto de su cuerpo". El legislador no define lo que debe entenderse por ese nuevo derecho. Sin embargo, es posible afirmar que se trata de un verdadero derecho subjetivo ${ }^{14}$ porque es reconocido a cada persona individualmente, releva del orden de los derechos de la personalidad, tiene carácter extrapatrimonial y su protec-

13 GAllOUX, Ch. "De corpore jus". Petites Affiches 149 , 14 de diciembre de 1994 , p. 18 ; BYK, Ch. "Statut du corps humain et pratiques biomédicales: à propos des lois bioéthiques françaises". Jal.Intern.Bioétb 1 , Vol. 7, 1996, p. 3; DUPRAT, M. "Statut du corps humain et pratiques biomedicales: une construction progressive". Petites Afficbes, 3 de julio de 1996, p. 4; Dict. Bioethique et Biotechnologies. "Statut du corps humain, de ses éléments et produits". Feuillets 16, 1 de febrero de 1998.

14 FENOUILLET, D. "Protection de la personne. Le corps humain". J.-Cl. Civil, artículo 16 al 16-12, fascículo 12 ; BYK, Ch. "la loi relative au respect du corps humain". JCP, 1994, I, p. 3788; THOUVENIN, D. "La personne et son corps: un sujet humain, pas un individu biologique". Petites Afficbes 149, 14 de diciembre de 1994 , p. 26. 
ción es asegurada por la apertura de una acción judicial. El artículo 16-2 prevé que el juez puede prescribir medidas propias para impedir o hacer cesar todo atentado ilícito a la integridad corporal ${ }^{15}$.

El derecho al respeto del cuerpo humano, erigido a la calidad de derecho subjetivo, se funda en dos principios fundamentales: el principio de la inviolabilidad del cuerpo humano (ítem 3.1.1) y el principio de su extrapatrimonialidad (item 3.1.2). Tradicionalmente invocados por la jurisprudencia en calidad de principios generales del derecho, ellos constituyen actualmente normas de derecho positivo destinadas a asegurar la protección de la dignidad de la persona.

\subsubsection{Principio de la inviolabilidad}

El cuerpo de la persona es intangible, noli me tangere. Siguiendo esta lógica el legislador francés consagra un principio de carácter general de integridad corporal. El artículo 16-1 inciso 2 del Código Civil proclama que "el cuerpo humano es inviolable". El enunciado tiene un sentido muy amplio. De una parte, no está permitido atentar contra el cuerpo ajeno, y de otra parte la ley se opone a que la persona atente contra la integridad de su propio cuerpo. El artículo engloba igualmente la prohibición de dañar la integridad física y la psíquica ${ }^{16}$.

No obstante, ciertos atentados a la integridad corporal pueden ser legítimos siempre que respondan a una finalidad previs-

15 De la misma manera que cada persona se beneficia del derecho a la intimidad de su vida privada, cada uno tiene derecho al respeto de su cuerpo.

16 CARBONNIER, J. "Droit civil, les personnes". Thémis: 5. París: PUF, 1996 , p. 20. ta por la ley ${ }^{17}$. Tal es el caso de la necesidad terapéutica de la persona fundada en su consentimiento libre y aclarado, como por ejemplo una intervención quirúrgica ${ }^{18}$. Paralelamente, la ley autoriza algunos atentados al cuerpo humano en caso de necesidad terapéutica del prójimo (donación de órganos), con fines de investigación científica (experimentaciones sin beneficio directo para la persona), con fines probatorios (examen comparado de sangre o de huellas genéticas) y hasta mercantiles (venta de cabellos, dientes o uñas), a lo cual conviene agregar la libertad reconocida a la mujer de recurrir a la interrupción voluntaria de la gestación dentro de las condiciones establecidas por el orden jurídico $^{19}$.

\subsubsection{Principio de la extrapatrimoniabilidad}

El legislador francés busca evitar que el cuerpo humano sea objeto de intercambios mercantiles. La imposibilidad de todo tipo de comercialización está consagrada en el artículo 16-3 del Código Civil, que prevé que "el cuerpo humano, sus elementos y sus productos no pueden ser objeto de un derecho patrimonial". Este enunciado es reforzado por el artículo 16-5 del mismo código, que establece "la nulidad de toda convención que tenga por objeto conferir un valor patrimonial al cuerpo humano".

17 FENOULLET, D. "Protection de la personne, Le corps humain". J.-Cl. Civil, artículo 16 al 16-12, fascículo. $12,87$.

18 Artículo 16-3: "Il ne peut être porté atteinte à l'intégrité du çorps humain qu'en cas de nécessité thérapeutique pour la personne $(. . .)^{n}$.

19 En Francia la interrupción voluntaria de la gestación es consagrada por una ley del 17 de enero de 1975 . 
El principio de la extrapatrimonialidad del cuerpo implica cuatro principales aplicaciones $^{20}$, a saber:

- Prohibición de asignar una remuneración a aquel que se presta a una experimentación (artículo 16-6 del Código Civil).

- Prohibición de asignar una remuneración a aquel que, con fines de un trasplante, se presta a la extracción de sus órganos, tejidos, células, sangre, espermatozoides, 6́vulos (artículo 16-6 del Código Civil) ${ }^{21}$.

- Nulidad de toda suerte de contrato de procreación o de gestación por cuenta de otro (artículo 16-7 del Código Civil). No importa que la convención sea anterior o posterior al nacimiento del ni-

20 CONSEIL D'ETAT. "Réflexions du Conseil d'État sur le droit de la santé". Eitudes et documents 49. La documentation Fransaise. Informe público, 1998, p. 278 et ss.

21 En el sistema jurídico francés la gratuidad y el anonimato constituyen condiciones fundamentales de la donación de órganos, tejidos, gametos o sangre humana. Esos dos principios (gratuidad y anonimato) son el corolario del principio de no-patrimonialidad del cuerpo humano.

A fin de asegurar el respeto de la prohibición de la comercialización de los órganos, gametos o sangre humana, el artículo 16-8 del Código Civil prevé que ninguna información que permita identificar, a la vez, a aquel que hace una donación de órganos y aquel que la recibe puede ser divulgada. Dentro de este mismo interés, el artículo 511-2 del código Penal establece que "el hecho de obtener de una persona uno de sus órganos contra un pago, cualquiera sea su forma, es penado con siete años de prisión y 700 mil francos de multa". Las mismas penas son aplicadas a aquellos que intervienen para favorecer la obtención de órganos ajenos a título oneroso y también a aquellos que favorecen la obtención de órganos, en esas mismas condiciones, provenientes de países extranjeros. Similares sanciones se imponen en caso de obtención de gametos o embriones humanos a título oneroso.

La ley de 1994 modifica la ley de 1952, relativa a la transfusión sanguínea, y la ley de 1949 , relativa al trasplante de córnea. Del mismo modo deroga las leyes de 1976 y 1991 que regulaban los trasplantes de órganos y la donación de gametos, respectivamente. ño, menos aun que sea concluida a título gratuito $\mathrm{u}$ oneroso. La nulidad de los contratos de maternidad de substitución es de carácter absoluto.

- Prohibición de la concesión de patentes reivindicando secuencias genéticas humanas (Código de la Propiedad Intelectual, artículo 611-7). En otras palabras, el conocimiento de la estructura total o parcial del genoma humano no puede ser objeto de patentes ${ }^{22}$.

Observemos, entonces, que en el cuadro de la legislación francesa el cuerpo humano no puede ser objeto de un derecho de propiedad que admitida el usus y el abusus ${ }^{23}$. Evitando que la persona aliene su propio cuerpo (órganos, sangre, tejidos o gametos), la ley impide, por vía de consecuencia, que la persona se aliene a sí misma. El cuerpo humano encarna la persona. A partir de allí, es posible afirmar que en el derecho francés la facultad de disponer del propio cuerpo constituye una de las manifestaciones de la libertad individual de la persona y no un derecho subjetivo ${ }^{24}$.

\subsection{Respeto de la integridad del género bumano}

La ley francesa preserva la integridad genética de la persona a través de la protección de su integridad física. El interés es, evidentemente, evitar que una manipu-

22 Observemos que el derecho de patentes concierne una creación intelectual y no un objeto corporal.

23 MEULDERS-KLEIN, Marie Therese. "La production de normes en matière de bioéthique". De la bioêthique a u bio-droit, NEIRINCK, C. LGDJ, 1994, p. 29; HERMITTE, Marie-Angele. "Le corps hors du commerce, hors du marchén. Archives de pbilosopbie du droit. Tomo 33. Sirey, 1988 , p. 323.

24 BAUDOUIN, M. Y LABRUSSE-RIOU, C. Produire l'bomme: de quel droit?, p. 191; CARBONNIER, J. Droit civil, les personnes. Themis: Paris: PUF, 1996 , pp. $25-26$ 
lación genética operada sobre la persona tenga una incidencia sobre la especie. Es en este sentido que el legislador introduce una regla destinada a la protección de la integridad de la especie humana.

Según el artículo 16-4 del Código Civil:

Nadie puede atentar contra la integridad de la especie humana.

Toda práctica eugenésica tendiente a la organización y a la selección de personas está prohibida.

Sin perjuicio de las investigaciones tendientes a la prevención y al tratamiento de enfermedades genéticas, ninguna transformación puede ser realizada a los caracteres genéticos con la finalidad de modificar la descendencia de una persona.

El artículo 16-4 se explica en razón de los últimos desarrollos de la biomedicina y de las desviaciones potenciales que ellas pueden conducir. Dentro del cuadro de la legislación francesa, atentar contra la integridad de la especie humana implica de un lado la posibilidad de modificar el patrimonio genético de la especie humana, y del otro, el eugenismo ${ }^{25}$. Estas dos hipótesis están excluidas de manera categórica porque vulneran el respeto de la dignidad humana.

La prohibición de realizar transformaciones genéticas ${ }^{26}$ que modifiquen la descendencia de la persona está destinada a asegurar la intangibilidad de la especie humana. La ley excluye así las modificaciones genéticas de la persona que repercutirían sobre el genoma humano ${ }^{27}$. Vale decir, in-

25 FENOUILLET, D. "La génétique humaine". J.-Cl. Civil, artículo 16 al 16-12, fascículo 30 y 32 .

26 Cuando la ley habla de transformaciones genéticas alude a las prácticas médicas terapéuticas o experimentales conocidas bajo el nombre de terapia genética. Precisemos que esta terapia utiliza diversas técnicas de genio genético para corregir defectos genéticos ligados a la aparición de ciertas enfermedades.

27 Es necesario subrayar la diferencia entre terapia genética germinal y terapia genética somática. Esta última tenta salvaguardar aquello que distingue a los seres humanos de otras especies. Para ello prohíbe los actos que atenten directamente contra las características humanas (transformaciones de las características genéticas de la persona) ${ }^{28}$ y los actos que podrían destruir la barrera entre las especies ${ }^{29}$ (acercando el ser humano a otras especies en el caso de que se introduzca en él genes extranjeros) ${ }^{30}$.

consiste en la transferencia de genes hacia las células somáticas (células no-sexuales) de un organismo constituido, reemplazando de alguna forma un transplante de órganos. En esas condiciones el cambio genético introducido no será hereditario. Contrariamente, la terapia genética germinal concierne a las células implicadas en la formación de gametos. En el ser humano, la única posibilidad de practicar esta terapia es inyectar un gen en las células de un embrión pre$\mathrm{CO}$ obtenido por fecundación in vitro. La práctica daría lugar entonces a un organismo del cual las células somáticas serian modificadas y que permitiría transmitir por esas células germinales esta modificación a su descendencia.

De donde resulta que lo que la legislación francesa prohibe es la terapia germinal porque toca la especie, modificando los caracteres genéticos de las células que contienen los genes hereditarios. Sólo la terapia genética somática está permitida. El legislador no ha querido cerrar las puertas a la esperanza de vencer, algún día, las enfermedades genéticas. COMITÉ CONSULTATTF NATIONAL D'ÉTHIQUE. Avis sur génétique et médecine: de la prédiction à la prévention. 30 de octubre de 1995; AUFRAY, Ch. Le génome bumain. París: Flammarion, 1996.

28 Cuando la ley limita la libertad de transformar los caracteres genéticos de la persona tiende a asegurar la intangibilidad de la especie, amenazada por experiencias científicas cuyas consecuencias sobre las futuras generaciones no se podrán conocer hasta dentro de muchos años. Sin embargo, esta intangibilidad de las características genéticas de la persona asegura también el respeto de la persona concernida (algunos autores hablan entonces de "derecho a la integridad genética" o "derecho a la identidad genética"). MICHAUD, J. "La thérapie génique". Droits de la personne: Les bio-droits. BAUDOUIN, J.L. Les Ed. Yvon Blais, 1997.

29 Imposible de manera natural a causa de la barrera de "interesterilidad" existente entre especies diferentes, el cruce interespecie es ahora posible gracias a los progresos de la genética.

30 Tal sería el caso de la fusión de un gameto humano con un gameto de otra especie, la implantación de 
En suma, atentar contra la integridad de la especie consiste en modificar la unidad del todo, alterar la especie infringiendo la esencia humana, la cual es común a todos los hombres (que hace del "ser" un "humano") y propia a ellos solos (que distingue al ser humano de otras especies) ${ }^{31}$.

El atentado contra la integridad de la especie humana puede igualmente resultar de la supresión, en el seno de la especie humana, de la diversidad genética ${ }^{32}$. Por ello, el artículo 16-4 del Código Civil excluye la selección programada fundada sobre criterios genéticos; en una palabra, la eliminación de aquellos seres humanos que serían portadores de "malos" genes. El numeral prohíbe las prácticas eugenésicas colectivas, es decir aquellas sometidas al control social y destinadas a aumentar o disminuir las cualidades físicas o mentales de las futuras generaciones ${ }^{33}$. Se trata en alguna medida de preservar el nacimiento de seres diferentes y de impedir la aparición de criterios tendientes a la "uniformización" de seres humanos ${ }^{34}$. Con el interés de fortalecer la

un embrión humano en el útero de otra especie, la introducción en un embrión de una especie fecundado con genes de una especie diferente. Cabe mencionar igualmente que ciertas experimentaciones realizadas, por ejemplo, en Estados Unidos (ratones manipulados con genes humanos, producción de hemoglobina humana por cerdos sobre los cuales habian trasplantado genes humanos) o en Holanda (autorización del Parlamento en 1993 de introducir un gen humano en un toro) aparecen prohibidas en Francia.

31 FENOUILLET, D. "La génétique humaine". J.-Cl. Civil, artículo 16 al $16-12$, fasciculo 30 y 32 .

32 GROS, François y Gérad HUBERT. Vers un andi-destin? Patrimoine génétique et droits de l'bumanité. Ed. Odile Jacob, 1992.

33 Con la prohibición expresa de la selección de personas bajo criterios genéticos, el legislador francés intenta hacer frente a las tesis de ciertos teóricas anglosajones que sustentan la supresión de "indeseables". La sombra de los horrores del genocidio nazi aparece latente en el enunciado del artículo.

34 THOUVENIN, D. "Les lois No 94-548 du 1er juillet 1994, № $94-654$ du 29 juillet 1994 ou comment construire un droit de la bioéthique". ALD, 1995, 149. prohibición, la ley prevé una figura penal específica ${ }^{35}$.

De otra parte, la prohibición de atentar contra la integridad de la especie humana, de poner en obra prácticas eugenésicas tendientes a la organización de la selección de las personas y las prácticas destinadas a modificar la descendencia de una persona condena, consecuentemente, toda práctica tendiente a la producción de seres humanos comportando un conjunto idéntico de genes $^{36}$. El legislador francés establece así, de manera implícita, el carácter ilegal de la clonación de seres humanos ${ }^{37}$.

Observemos que la ley consagra una posición de principio. Prohíbe la selección eugenésica pero autoriza el estudio genético de las características de la persona (ítem 3.2.1) y su identificación por sus huellas genéticas ${ }^{38}$ (ítem 3.2.2).

\subsubsection{Estudio genético de las características de la persona}

La ley define claramente la finalidad aceptable de la práctica de tests genéti$\cos ^{39}$. Según el artículo $16-10$, inciso 1 del

35 El artículo 511-1 del Código Penal establece que "el hecho de poner en obra una práctica eugenésica tendiente a la selección de las personas es sancionado con veinte años de reclusión criminal".

36 COMITÉ CONSULTATIF NATIONAL D'ÉTHIQUE. Réponse au Président de la République au sujet du clonage reproductif, Avis № 54, 22 de abril de 1997; JACQUINOT, C. "Les droits du génome humain". Gaz. Pal., 2 de enero de 1998 , p. 32.

37 Actualmente, el legislador francés estudia la posibilidad de proclamar una prohibición formal explícita de la clonación.

38 Los tests y las huellas genéticas son dos técnicas que permiten, a partir de una muestra de tejido, de raíz de cabello o de una gota de sangre (si se encuentra un poco de ADN) determinar las caracteristicas genéticas de una persona o de proceder a su identificación.

39 Se trata aquí de un primer tipo de test que consiste en el estudio de las caracteristicas genéticas de la persona por su examen genético, es decir, lo que se llama corrientemente la carta genética. 
Código Civil, "el estudio genético de las características de una persona no puede ser realizado, salvo con fines médicos o de investigación científica".

El texto supedita el estudio de las características genéticas de la persona a una finalidad de orden médico o científico ${ }^{40}$. La posibilidad de despistar enfermedades de origen genético es permisible con el propósito de curar a la persona. En el mismo sentido, la investigación científica concierne el desarrollo de conocimientos destinados al descubrimiento o al perfeccionamiento de tratamientos médicos ${ }^{41}$.

Cabe precisar que la finalidad médica a la cual alude el artículo no se limita a la aplicación de una terapia determinada a una u otra persona ${ }^{42}$. En efecto, si los tests genéticos permiten poner en evidencia la predisposición a una enfermedad o la facultad de transmitir un gen deficiente, la realización de tests genéticos no desemboca necesariamente en un tratamiento curativo ${ }^{43}$. Asimismo, los estudios de las enfermedades genéticas requieren la colaboración de grupos de familias, aquí la investigación tiene por finalidad esencial remarcar la existencia de una anomalía, pero no necesariamente la de curar a esas personas ${ }^{44}$.

40 DICT. BIOÉTHIQUE BIOTECHNOLOGIES. "Tests génétiques". Feuillets 12, 1 de noviembre de 1996, p. 2481.

41 El Código Penal (artículo 226-26) sanciona el hecho de desviar de su finalidad médica o de la investigación científica las informaciones obtenidas al cabo del estudio de las características genéticas de una persona con un año de prisión y cien mil francos de multa.

42 Observemos al respecto que el término "finalidad médica" es mucho más extenso que el término "finalidad terapéutica".

43 RUFFIÉ, J. Naissance de la médecine prédictive. Éditions Odile Jacob, 1993.

44 THOUVENIN, D. "Les lois No 94-548 du ler juillet 1994, № 94-654 du 29 juillet 1994 ou comment construire un droit de la bioéthique". ALD, 1995, p. 149.
Por otra parte, la realización de los estudios o tests genéticos está subordinada al consentimiento expreso de la persona. El consentimiento es una condición obligatoria impuesta al médico, quien no puede efectuar ningún test $s i n$ el acuerdo previo de su paciente ${ }^{45}$. El Código Penal, artículo 226-25, resguarda el cumplimiento de la exigencia estableciendo que el hecho de proceder al estudio de las características genéticas de una persona con fines de orden médico, sin haber obtenido su consentimiento, es sancionado con una pena privativa de la libertad de un año y $100 \mathrm{mil}$ francos de multa.

Sin embargo, la eficacia de la ley es en muchos casos relativa ${ }^{46}$. Basta percatarse que los exámenes genéticos, por ejemplo a partir de una muestra de sangre, son de fácil realización y que por lo mismo pueden ser efectuados no solamente sin el acuerdo de la persona sino también sin su conocimiento.

\subsubsection{Identificación de la persona por sus buellas genéticas}

Fuera de toda cuestión médica, la identificación de la persona por sus huellas genéticas ${ }^{47}$ es admitida como medio de prueba. El artículo 16-11 del Código Civil establece que:

... la identificación de una persona por sus huellas genéticas no puede ser realizada, salvo en el cuadro de medidas de encues-

45 EDELMAN, B. "Génétique et liberté". Droits 13, 1991, p. 31.

46 BYK, Ch. "La loi relative au respect du corps humain". JCP, 1994, p. 3788.

47 El término "huellas genéticas" se lo debemos al británico Alec Jeffreys, quien publica en 1985 su descubrimiento y denomina "huellas digitales genéticas" a la puesta en evidencia de esos perfiles de ADN. 
ta o de instrucción en un proceso judicial o con fines médicos o de investigación científica.

Tomando en cuenta que el análisis del ADN permite conocer la organización genética propia de cada individuo y por lo tanto identificarlo, el legislador autoriza la realización de dichos tests en el cuadro de un proceso judicial penal o civil ${ }^{48}$. En el ámbito civil, la identificación genética de la persona puede darse únicamente en ejecución de una medida judicial ordenada por el juez, tendiendo al establecimiento o a la contestación de un vínculo de filiación, bien sea para la obtención o supresión de alimentos.

En materia penal, la identificación biológica puede ser de gran utilidad, por ejemplo para la identificación del cadáver de la víctima a través del análisis de su piel o cabellos. De la misma forma, resulta útil para identificar al autor de un crimen o de una violación por el análisis de su esper$\mathrm{ma}^{49}$. En estos casos, la identificación genética de la persona no requiere de su consentimiento.

\section{PROCREACIÓN DEL SER HUMANO}

El legislador francés consagra la intervención médica en materia de procreación en su principio y sus aplicaciones principales. Utiliza la expresión de "asistencia médica a la procreación (AMP)" 50 , de don-

48 Dict. Bioéthique Biotechnologies "Tests génétiques". Feuillets 12, 1 de noviembre de 1996, p. 2481.

49 La primera identificación de esta naturaleza se realizó en 1987: un caso de violación en el Reino Unido.

50 Hasta hace algunos años la expresión utilizada era la de "procreación artificial", por oposición a la procreación natural o carnal. La expresión alude al empleo de artificios o astucias médicas destinadas a pro- de se desprende que el objeto de la ley es reglamentar las técnicas médicas que facilitan la procreación y no la procreación propiamente dicha ${ }^{51}$.

Sistemáticamente se establece una diferencia entre los aspectos sanitarios y civi$\mathrm{les}^{52}$. Se ha creado un nuevo capítulo en el Código de la Salud Pública destinado a regular las prácticas médicas autorizadas (métodos, formas de asistencia) y las condiciones de su aplicación. Paralelamente se introduce en el Código Civil algunas normas para regular las consecuencias de la procreación que ha sido médicamente asistida, es decir, aquellas referentes a la filiación del recién nacido.

La ley define la asistencia médica a la procreación como un conjunto

... de prácticas clínicas y biológicas que permiten la concepción in vitro, la transferencia de embriones y la inseminación artificial, así como toda técnica de efecto equivalente, permitiendo la procreación fuera del proceso natural ${ }^{53}$.

Constatemos que la ley autoriza los dos procedimientos clásicos (la inseminación artificial y la fecundación in vitro), pero no excluye la utilización de nuevos métodos.

vocar la gestación más allá de la sexualidad infértil de la pareja. El legislador francés ha preferido la expresión "asistencia médica a la procreación".

51 BAUDOUIN, J.L. y C. LABRUSSE-RIOU. Produire l'bomme: de quel droit? Etude juridique et étbique des procreations antificielles. París: PUF, 1987; TERRÉ, F. L'enfant de l'esclave. gênétique et droit. Paris: Flammarion, 1987.

52 GALLOUX, J.C. "Bioéthique. Les lois du 29 juillet 1994", Petites Afficbes 149, 14 de diciembre de 1994; FEUILLET-LE-MINTIER, B. L'application des lois bioétbique du 29 fuillet 1994. CRJO, Ministère de la Justice, octubre de 1998; Id. L'embryon bumain, approche multidisciplinaire, Economica, 1996; Dict.. Bioéthic et biotechnologies. "Assistance médicale à la procréation". Feuillets 17, 1 de junio de 1998, p. 109.

53 Código de la Salud Pública, artículo L. 152-1. 
El carácter general de la definición deja abierta la posibilidad de que los pacientes se beneficien de la continua evolución de los progresos científicos, pero aparece también como una solución permisiva ${ }^{54}$.

Sin embargo, conviene poner en evidencia que en la legislación francesa las condiciones de la aplicación de técnicas médicas no dependen de deontologías médicas particulares ni de la autonomía de la voluntad de los pacientes. Con el interés de garantizar buenas condiciones sanitarias a los pacientes y tranquilizar a la sociedad sobre la deontología que rige estas actividades, cierto número de reglas determina quién y en $q u e ́$ condiciones se puede beneficiar de la AMP (item 4.1). Correlativamente, la ley impone obligaciones y limites a la actividad del cuerpo médico (ítem 4.2).

\subsection{El acceso a la asistencia médica a la procreación}

En el ordenamiento jurídico francés, la asistencia médica a la procreación no constituye un modo de procreación de conveniencia personal. El régimen jurídico adoptado reposa sobre la idea de que la asistencia médica constituye una forma subsidiaria, y no alternativa, a la procreación sexual ${ }^{55}$. En consecuencia, el legislador francés se rehúsa a hacer de las nuevas tecnologías de reproducción el medio de obtención del pretendido "derecho al hijo" ${ }^{26}$. Busca más bien equilibrar la liber-

54 Una definición demasiado general puede dar lugar a desviaciones, al alargamiento de indicaciones de fecundación in vitro y a la aplicación de métodos en estado aún experimental.

55 MATTEI, J.F. "La vie en questions". La documentation Française, 1994, p. 161; BAUDOUIN, J.1. y C. LABRUSSE-RIOU. Produire l'bomme: de quel drott? Etude juridique et étbique des procréations artificielles, p. 165.

56 CONSEIL. D'ETAT. "Sciences de la vie: de l'éthique au droit". La documentation française, 1988, p. 57. tad de procrear, a la cual puede tener naturalmente vocación toda persona, con el respeto de los derechos y el interés del futuro niño o niña.

En derecho francés, el deseo (legítimo) de procrear no constituye un derecho subjetivo susceptible de ser reivindicado en cualquier circunstancia. Un conjunto de condiciones de fondo (item 4.1.1) y de forma (item 4.1.2) subordina el acceso a la asistencia médica a la procreación. Ellas tienden a evitar la perturbación de los pilares jurídicos sobre los cuales reposan las estructuras familiares tradicionales.

\subsubsection{Condiciones de fondo}

La ley limita las actividades de asistencia médica a la procreación limitando los proyectos parentales susceptibles de ser satisfechos. Según el artículo L. 152-2 del Código de la Salud Pública “... la asistencia médica a la procreación está destinada a responder a la demanda parental de una pareja". La idea es que la procreación "artificial" debe imitar la procreación carnal $^{57}$. Esta última es, normalmente, el resultado de relaciones bisexuales consentidas. La ley exige entonces que el deseo de dar "artificialmente" la vida sea compartido por 10 dos miembros de la pareja ${ }^{58}$.

Sin embargo, el acuerdo de dos voluntades concordantes en un proyecto parental común es insuficiente para desencadenar el proceso de asistencia médica. El legislador ha bosquejado una noción civil de pareja parental ${ }^{59}$. La pareja susceptible de

57 CARBONNIER, J. Droit civil, la famille, l'enfant, le couple. Tomo 2. 20a. edición. Thémis. París: Puf, 1999, p. 394.

58 En consecuencia, la asistencia médica a la procreación no será concedida a la solicitud de una mujer sola, ya sea soltera o divorciada.

59 BRUNETTI-PONS, C. "La notion juridique de couple". 
obtener el beneficio de la asistencia médica para procrear debe cumplir estrictas condiciones. El Código de la Salud Pública precisa que "el hombre y la mujer que forman la pareja ${ }^{60}$ deben estar vivos ${ }^{61}$, en edad de procrear ${ }^{62}$, casados o en medida de probar una vida común de al menos dos años".

Aparte de la voluntad manifestada por la pareja de tener un hijo, la ley restringe la asistencia a la procreación a una finalidad de carácter médico ${ }^{63}$. La ley establece que "la asistencia médica a la procreación tiene por objeto remediar la infertilidad de la cual su carácter patológico ha sido diagnosticado ${ }^{64}$. Puede también tener por objeto evitar la transmisión al niño de una enfermedad de una particular gravedad"65.

Colloque Université de Reims. Economica, 1998; Id "L'émergence de la notion de couple en droit civil" RTD civ., 1999, p. 27; DREIFUSS-NETTER, N. "Adoption ou assistance médicale à la procréation: quelles familles?". D., 1998, p. 100; DEKEUWER-DÉFOSSEZ, M. "Reflexions sur les mythes fondateurs du droit contemporain de la famille". RTD cit., 1995, p. 22.

$60 \mathrm{Al}$ exigir que los beneficiarios de la asistencia médica sea una pareja compuesta por un hombre y una mujer, la ley se opone en consecuencia a que las parejas de homosexuales o transexuales accedan a las tecnologías de la reproducción.

61 Se descarta así la posibilidad de la procreación postmortem.

62 La ley toma en cuenta únicamente la infertilidad de carácter patológico. Implícitamente excluye la asistencia médica en aquellos casos en que la imposibilidad de procrear es consecuencia del transcurso irreparable del tiempo. El objetivo es evitar ciertos excesos como aquellos ocurridos en Italia o Inglaterra donde mujeres de 50 y aun de 60 años han podido concebir "artificialmente".

63 CORNU, G. Droit civil, la famille. Op. cit., № 300 , p. 415.

64 La ley impone que un médico diagnostique que la ineficacia de la función procreadora tenga un origen patológico. Lo cual significa que la ley toma en cuenta únicamente ciertas infertilidades, aquellas de carácter natural ligada a la edad de la pareja son descartadas.

65 Fuera de la esterilidad patológica, la asistencia médica a la procreación es permitida cuando existe el ries-
Remarquemos entonces que la puesta en obra de las prácticas médicas no está abandonada al libre arbitrio de los particulares. No solamente la ayuda médica está circunscrita a una finalidad de orden terapéutico, un remedio de la imposibilidad orgánica de procrear y no una nueva manera de dar la vida, sino que va más allá. Cuando la ley exige que la pareja beneficiaria de la AMP esté constituida por un hombre y una mujer vivos formando además una unión estable, afirma implícitamente que "todo niño tiene la vocación natural y legítima de nacer y crecer en el seno de una familia biparental" ${ }^{16}$. Esta última es la única garantía del respeto de las estructuras naturales de la filiación, en sus ramas materna y paterna.

Podemos entonces afirmar que el legislador francés, a diferencia de otros países europeos $^{67}$, no se limita a regular las actividades y prácticas médicas sino que ha hecho, de manera pertinente, la elección de un modelo sociocultural.

go de transmitir al niño una enfermedad de carácter grave. El concepto de enfermedad de una particular gravedad engloba las enfermedades genéticas y ciertas enfermedades virales graves como el sida.

66 CORNU, G. y C. LABRUSSE-RIOU, Droit de la filiation et progrès scientifiques. Economica, 1982; HAUSER, J. "Filiation, identification génétique. Procréation médicalement assistée". J.-C. Civil, artículo 311-19, 311-20, 2, 1997.

67 En Inglaterra el artículo 13 inciso 5 de la ley de 1990 dispone que el médico, antes de practicar una asistencia médica a la procreación, debe tener en cuenta el interés del futuro niño (comprendiendo la necesidad de tener un padre); sin embargo, a pesar de la referencia expresa a la imagen masculina, la ley no excluye que una mujer, sola u homosexual, pueda beneficiarse de una procreación "artificial". La misma posición ha adoptado el legislador español. WARNOCK, M. Rapport de la Commission d'enquête concernant la fécondation et l'embryologie bumaines Royaume-Uni, julio de 1984, La documentation Franşatse, 1985; MARTÍNEZ CALCERRADA, L. Derecbo tecnológico, la nueva inseminación artificial (estudio Ley 22 de noviembre 1988). Madrid, 1990. 


\subsubsection{Condiciones de forma}

Con el interés de proteger al niño que se va a traer al mundo, el legislador adopta una serie de precauciones. La aplicación de las nuevas tecnologías de la reproducción está sujeta a un conjunto de garantías relativas a la manifestación de voluntad de los futuros padres. Según el artículo L. 152 del Código de la Salud Pública, "la asistencia médica a la procreación está destinada a responder a la demanda parental de una pareja que debe consentir previamente la transferencia de embriones o la inseminación".

El consentimiento del hombre y de la mujer que forman la pareja tiene por objeto la intervención médica de procreación asistida efectivamente practicada ${ }^{68}$. Este consentimiento debe ser libre e informado ${ }^{69} \mathrm{y}$, es importante subrayar, debe comportar la aceptación de la obligación de asumir el status de padre y las responsabilidades que esta condición implica ${ }^{70}$.

La expresión del consentimiento está rodeada de garantías particulares en función al capital genético necesario para la procreación. Tratándose de una inseminación intraconyugal, el consentimiento es asimilado al consentimiento necesario para un acto médico. Dado que la intervención no altera el origen biológico del niño ni su filiación, el legislador no estimó necesario imponer otras formalidades.

Contrariamente, cuando se recurre a una donación de gametos el consentimiento del futuro padre (padre legal) reviste

68 TERRÉ, F. y D. FENOUILLET. Droit civil, les personnes, la famille. París: Précis Dalloz, 1996, p. 804.

69 La ley exige una serie de entrevistas particulares entre la pareja y un equipo médico pluridisciplinario.

70 El artículo 311-20 del Código Civil establece una obligación de carácter general, a cargo de aquel que consiente a la asistencia médica a la procreación, de reconocer al niño así nacido. una importancia capital y la ley impone un carácter solemne. El artículo 311-20 del Código Civil dispone que:

... los esposos o concubinos que recurren a una asistencia médica a la procreación necesitando la intervención de un don de gametos, deben dar su consentimiento ante el juez o el notario quien les informa sobre las consecuencias del acto respecto a la filiación.

El legislador tiende así, primero, a asegurarse de la realidad del consentimiento, y segundo, a eliminar la posibilidad del rechazo de las responsabilidades paternas una vez que el nacimiento se produzca ${ }^{71}$.

En lo que se refiere al don de embrión, la ley prevé solemnidades suplementarias $^{72}$. El procedimiento se inspira en el modelo de la adopción.

En primer lugar, se exige que la pareja que da origen a la concepción del embrión manifieste su consentimiento por escrito ante un médico autorizado a practicar actividades de Asistencia Médica a la Procreación (AMP). Este documento es dirigido al Tribunal de Grande Instancia.

En segundo lugar, la pareja que desea acoger el embrión debe manifestar su consentimiento ante el juez, quien verifica si aquella cumple las condiciones exigidas para el acceso a la asistencia médica y si está en capacidad de ofrecer al futuro niño las garantías necesarias para su desarrollo

71 HAUSER, Jean. "Filiation". J.-Cl.Civil, artículo 311-19 y 311-20; NEIRINCK, C. "Le droit de la filiation et la procréation médicalement assistée". Petites Affiches 149,14 de diciembre de 1994, p. 59.

72 El procedimiento destinado a acoger embriones es autorizado a título excepcional. Concierne siempre embriones concebidos inicialmente para satisfacer el deseo de procrear de una primera pareja que decide finalmente no continuar su proyecto parental. En cuanto a la pareja que desea acogerlos, esta debe presentar una esterilidad bilateral o ser portadora de una anomalía genética grave. El acto está sometido a las reglas de anonimato y gratuidad. 
en los planos familiar, educativo y psicológico $^{73}$. El don de embrión aparece así como una suerte de adopción prenatal ${ }^{74}$.

\subsection{El cuadro institucional de asistencia médica a la procreación}

La legislación francesa trasluce el deseo de preservar la procreación del ser humano lejos de acuerdos, más o menos loables, entre particulares. La asistencia médica a la procreación está confinada dentro de una reglamentación estricta. De una parte, la ley confiere a la autoridad médica la responsabilidad de decidir, en último lugar, la oportunidad de su aplicación. Luego de haber diagnosticado la necesidad terapéutica de la intervención, corresponde al médico efectuar el control social de la solicitud parental de los candidatos (item 4.2.1). De otro lado, la ley somete la actividad del cuerpo médico a un control administrativo destinado a asegurar su conformidad con los principios definidos por la ley (item 4.2.2).

\subsubsection{Control social}

La asistencia médica a la procreación no es sistemáticamente prodigada a todo aquel que la solicita. El artículo L. 152-10 del Código de la Salud Pública dispone que el acceso a la asistencia médica "debe

73 Sanciones penales garantizan el cumplimiento del procedimiento establecido. El artículo 511-16 del Código Penal prevé que el hecho de obtener embriones humanos $\sin$ respetar las condiciones previstas por la ley es sancionado con siete años de prisión y $700 \mathrm{mil}$ francos de multa.

74 CORNU, G. Droit civil, la famille. Op. cit, № 300 , p. 411; FAURE, G. "L'accueil d'embryon". JCP 50, 15 de diciembre de 1999 , p. 2233; TERRASSON DE FOUGERES, M. "Le devenir des embryons conçus in vitro après dissolution du couple parental". RD sanit. soc., 1996, p. 623. estar precedido de entrevistas particulares de los solicitantes con los miembros de un equipo pluridisciplinario del centro autorizado a practicar dichos actos".

En el curso de esas entrevistas, el equipo médico comprueba que la pareja cumple con las condiciones exigidas por la ley para obtener la asistencia médica a la procreación ${ }^{75}$. Enseguida, corresponde al equipo médico informar a los candidatos las posibilidades de éxito y fracaso de la intervención, las dificultades de su realización, así como el estado actual de los conocimientos respecto a la salud de los niños nacidos a partir de estas técnicas. Esta información permite a los interesados dar un consentimiento libre e informado a la realización de la intervención.

En último término, las entrevistas previas tienen por objeto permitir al equipo pluridisciplinario verificar las motivaciones de la pareja solicitante ${ }^{76}$. Los médicos deben constatar que el nacimiento es deseado conjuntamente por el hombre y la mujer que forman la pareja, que su motivación es el anhelo de tener un hijo, criarlo y educarlo juntos ${ }^{77}$.

La ley reconoce al cuerpo médico la facultad de postergar la intervención o de rechazar la solicitud de asistencia médica, en caso de dudas serias respecto de la situación de los interesados o a su motivación $^{78}$. En la hipótesis positiva, y si los can-

75 El equipo médico deberá constatar la esterilidad de la pareja, solicitará además el certificado de matrimonio o los documentos que acrediten que la pareja tiene una relación estable de por lo menos dos años.

76 MONTAGUT, J. "L'assistance médicale à la procréation à t'heure de son réexamen". Médecine \& Droit 34, 1, 1999.

77 El legislador desea que la pareja sea consciente de la situación particularmente grave que enfrentará al recurrir a un don de gametos.

78 RAYMOND, G. "L'assistance médicale à la procréation". JCP 20, I, 1994, p. 3796; DEMAY DE GOUSTINE, M. "Procréation médicale et pouvoir médical". RD sanit. soc., 1996, p. 13. 
didatos persisten en su deseo de procrear, deberán reiterar su voluntad confirmando su solicitud parental.

\subsubsection{Control administrativo}

En Francia, la creación y el funcionamiento de centros médicos de procreación asistida no resulta de la libre iniciativa. Los múltiples cuestionamientos de orden ético acerca de la posibilidad de disponer, sin ningún control, de gametos y embriones humanos justifican la adopción de un conjunto de normas que regulan de manera estricta las prácticas médicas. Todas las actividades de asistencia médica a la procreación son sometidas a una autorización administrativa previa ${ }^{79}$.

La creación, en 1988, de la Comisión Nacional de Medicina y de Biología de la Reproducción y del Diagnóstico Prenatal (CNMBRDP) constituye un paso seguro hacia la institucionalización de un control administrativo de la asistencia médica a la procreación. La ley promulgada en 1994 consagra su existencia legal y la dota de un régimen legal ${ }^{80}$.

Esta comisión está encargada de pronunciarse sobre las solicitudes de autorización para el funcionamiento de centros médicos de asistencia a la procreación y de centros pluridisciplinarios de diagnóstico prenatal. Asimismo, debe examinar las solicitudes de autorización de los profesiona-

79 COMITÉ CONSULTATIF NATIONAL D'ÉTHIQUE. Avis sur les problèmes éthiques nés des techniques de reproduction antificielle 3, 23 de octubre de 1984; Avis relatif aux recbercbes et utilisation des embryons bumains in vitro à des fins médicales et scientifiques 8,15 de diciembre de 1986 .

80 ICT. BIOÉTHIQUE ET BIOTECHNOLOGIES. "Commission nationale de médecine et de biologie de la reproduction et du diagnostic prénatal" Feuillets 8, 1 de noviembre de 1995, p. 531. les de la salud que deberán efectuar esas intervenciones.

Los centros son sometidos a un régimen de autorización particular según la naturaleza de sus actividades ${ }^{81}$. La autorización para el personal médico es otorgada en función del examen de su especialización, calificación y experiencia ${ }^{82}$. Ambas autorizaciones son temporales (por un período de cinco años solamente) y renovables previa evaluación.

La comisión participa también en el seguimiento y evaluación del funcionamiento de los establecimientos y laboratorios autorizados. En ese sentido, dispone de la facultad de emitir pronunciamiento, en caso de existir la necesidad de revocar autorizaciones precedentemente dadas.

Por ejemplo, en el caso de violación de las prescripciones legislativas o reglamentarias que rigen la asistencia médica a la

81 Con la finalidad de restringir el número de centros médicos susceptibles de obtener la autorización, la ley impone un conjunto de reglas de seguridad sanitaria y una serie de condiciones técnicas de funcionamiento. Además prevé que el tratamiento y conservación de gametos, la fecundación in vitro y la conservación de embriones son reservados a establecimientos públicos de salud con fines no lucrativos. Contrariamente, la extracción de gametos y la transferencia de embrión pueden realizarse también en establecimientos de salud privados.

82 La comisión verifica que los médicos y biólogos sean titulares de los diplomas requeridos y que acrediten la experiencia exigida. Por ejemplo, para las actividades destinadas a la extracción de ovocitos y transferencia de embriones, en vista de su implantación in utero, el médico debe ser doctor en ginecología obstétrica, haber seguido una especialización en medicina de la reproducción y justificar una experiencia en ese dominio.

Para efectuar actividades biológicas (tratamiento y conservación de gametos, realización de fecundaciones in vitro), el profesional de salud debe ser médico especializado en biología médica o farmacéutico biólogo titular de una especialización en biología de la reprodúcción. En todos los casos, debe acreditar una experiencia suficiente en la manipulación de gametos humanos. 
procreación, si la deontología en la cual se desarrollan las actividades médicas no responde a los principios y objetivos determinados por la ley, o aun en el caso de resultados insatisfactorios, entre otros. Asimismo, entrega cada año al ministro del ramo un informe sobre la evolución de la medicina y la biología de la reproducción y del diagnóstico prenatal ${ }^{83}$.

Instituyendo un verdadero control administrativo de las actividades de extracción del material biológico humano (órganos, tejidos, gametos, sangre) y de las actividades de asistencia médica a la procreación, el ordenamiento jurídico francés salvaguarda las prácticas médicas de riesgos de desvíos, abusos, tráficos comerciales y de la creación de un "mercado" de la procreación humana ${ }^{84}$.

\section{CONCLUSIÓN}

A modo de conclusión, podemos preguntarnos si la legislación francesa sería aplicable a nuestro medio. La respuesta es, en principio, negativa. La misión del jurista no es la de transformarse en un importador de instituciones jurídicas extranjeras.

La transposición geográfica de leyes es asunto que exige especial cautela, pues una ley que podría ser buena en un determinado medio, no lo será necesariamente en otro.

LAJARTRE, A. de. "Les lois bioéthiques et le contrôle administratif des établissements", en FEUILLET-LEMINTIER, B. Les lois bioétbique à l'ẹpreuve des fails. París: PUF, 1999, p. 283.

84 AUBY, J.M. "Les aspects administratifs de l'assistance - médicale à la procréation et des prélèvements sur le matériel biologique humain ${ }^{n}$. Petites Afficbes 149,14 décembre 1994, p. 16.
Al mismo tiempo, hoy parece poco atinada la posibilidad de promulgar una nueva ley a ciegas, es decir, sin el conocimiento de la legislación extranjera y de la experiencia extranjera. Allí radica precisamente la importancia del estudio de la legislación comparada. La ley extranjera es útil en cuanto constituye un modelo referencial, una guía en la construcción del derecho nacional.

La necesidad de la adopción de leyes nacionales en materia de bioética deberá resultar del análisis de nuestro contexto social y, dado el caso, éstas deberán responder a nuestros valores socioculturales y a la idiosincrasia de nuestro pueblo. 